\title{
Representações de Simón Bolívar: de herói da independếncia para simplesmente humano
}

p. $104-114$

Diana Milena Heck ${ }^{1}$

\section{Resumo}

Simón Bolívar foi e ainda é um nome que evoca o mito e um dos principais heróis do processo de independência das colônias espanholas na América Latina. Levando em consideração o fato histórico e a importância da figura de Bolívar para os Estudos Culturais, pretende-se desenvolver neste trabalho uma comparação entre o romance O General em seu labirinto, de Gabriel García Márquez (1989) - que traz um outro olhar dessa figura real e histórica, retirando o carácter de mito e transformando-o em humano - e o filme Libertador (2013), - que preserva a imagem que a História desenhou de Bolívar - a fim de perceber como ocorre a desconstrução da figura heroica e histórica de Simón Bolívar pela obra do escritor colombiano, e, ao mesmo tempo, a valorização da personagem enquanto mito histórico e herói da independência, na obra cinematográfica.

Palavras-chave: Cinema. Desconstrução. Literatura. Representação. Simón Bolívar.

\section{REPRESENTATIOS OF SIMÓN BOLÍVAR: FROM INDEPENDENCE'S HERO TO A SIMPLY HUMAN}

\begin{abstract}
Simón Bolívar was and still is a name that evokes the myth and one of the main heroes of the independence of the Spanish colonies process in Latin America. Taking into account the historical fact and the importance of Bolivar for the Cultural Estudies, pretend to develop in this paper a comparison between the novel The General in His Labyrinth, by Gabriel García Márquez (1989) - which brings another look at this real figure and historical, removing the myth of character and turning it into human - and the film Libertador (2013) - which preserves the image that history drew Bolivar - in order to understand how does the deconstruction of the heroic and historical figure of Simón Bolívar the work of the Colombian writer, and at the same time, the appreciation of the character as historical myth and hero of independence, in the cinematographic work.
\end{abstract}

Keywords: Cinema. Deconstruction. Literature; Representation. Simón Bolívar.

\section{Introdução}

Quando se fala no descobrimento da América aborda-se, geralmente, como Colombo fez para chegar até essa nova terra e conquistá-la. Apesar de hoje ser muito evidenciada a condição da conquista, pela extrema violência, ainda se comemora mais do que se denuncia tal fato histórico. Naturalmente, o indivíduo que reside no espaço que compreende a América Latina, é fruto de um processo e de uma educação colonizadora, sendo, talvez por isso, condicionado a acreditar

1 Doutoranda em Letras, área de Concentração Linguagem e Sociedade, sob a orientação da Prof ${ }^{a}$ Dr Regina Coeli Machado e Silva, da Universidade Estadual do Oeste do Paraná - UNIOESTE. 
que a conquista da América foi um fato histórico de relevância heroica e que sem tal acontecimento não estaria neste espaço e talvez nem existisse.

A educação e o pensamento não foram condicionados para que a povo, que hoje vive neste espaço, pensasse no que de fato aconteceu para que Colombo chegasse a essa região. Já era um espaço conhecido? Os conquistadores sabiam que encontrariam muitas riquezas?

$\mathrm{Na}$ realidade, o descobrimento da América, chamado de "Novo Mundo", aconteceu por um acaso, pois a ideia inicial de Colombo era chegar até as Índias por uma nova rota, lugar no qual os espanhóis e portugueses iam buscar ouro e especiarias não existente na Europa.

Essa importante expedição, liderada por Colombo, chega ao "Novo Mundo" em 1492. A partir desta data, sabe-se que o resultado desse novo achado não foi nada agradável para o povo que já habitava esse espaço.

Violência, dizimação de todo um povo e cultura, imposição da língua, da religião, regime de escravidão, sentimento de inferioridade são marcas que perduram até hoje no cerne da cultura e História da América Latina.

Independente de terem sido os espanhóis ou portugueses, o processo adotado foi violento da mesma maneira e depois de muito tempo calados, enfim, surgem os estudos pós-coloniais que ajudam o sujeito da contemporaneidade a entender a violência sofrida e o preconceito que perduram até hoje em todos os países que foram colonizados ou que colonizaram/escravizaram um povo, como é o caso da escravidão, nos EUA, por exemplo.

Para este trabalho, no entanto, o foco de pesquisa será sobre a América colonizada pelos espanhóis, que hoje compreendem todos os países da América Latina, exceto o Brasil, colonizado pelos portugueses.

Sabe-se que na História da colonização e, posteriormente, a luta pela reconquista da América, há inúmeras figuras marcantes que contribuíram para ambos os processos. De um lado, Colombo, responsável pelo descobrimento do "Novo Mundo" e, de outro, além de inúmeros homens que batalharam para a retomada de seus territórios, por direito, está uma das personagens mais conhecidas, que é Simón Bolívar.

Além do retrato que a História fez de todas essas figuras lendárias, tem-se, também, a retratação dos mesmos na Literatura, no cinema e nas Artes, em geral.

O foco de pesquisa deste trabalho centrarse-á na representação de Simón Bolívar na obra cinematográfica, Libertador (2013), e na obra literária de Gabriel García Márquez, O general em seu labirinto (1989), estabelecendo um estudo comparado entre ambas a fim de perceber como se delineia a figura heroica e humana de um dos mais importantes autores da luta pela independência da América Latina.

\section{Simón Bolívar: menos herói, mais humano}

Bolívar, figura lendária na História, conhecido, se não mundialmente, na América Latina como uma das personagens que colaborou com a independência de territórios que estavam sob domínio dos espanhóis, bem como pela fundação de diversas nações, como Venezuela, Colômbia, Peru, Equador e Bolívia, contribuindo, assim, com o processo de descolonização desses territórios, que outrora haviam sido tomados pelos espanhóis sob violência e tirania.

Com tantos fatos importantes e tantas conquistas, impossível essa figura não ser descrita com o mesmo louvor de todos os heróis mundiais. Bolívar representa, até hoje, o ideal de herói da reconquista, da independência das colônias espanholas para se tornarem novamente livres. 
Ele está no mesmo patamar, senão acima, da representação da Princesa Isabel, no Brasil, que atuou na libertação dos escravos, ou de Abraham Lincoln, pela emancipação dos mesmos, nos EUA. A representatividade dessas figuras é de extrema importância para a História dessas nações, pois são um marco de ruptura de condições de escravidão, servidão, colonização e, consequentemente, extrema violência e desumanização de uma parcela da sociedade que, simplesmente, não tinha o direito de ser denominado como ser humano.

Filho de aristocratas espanhóis, Bolívar era um homem que vinha de uma classe social elevada e, consequentemente, teve acesso à educação. Era um homem culto e com uma situação financeira confortável. Muito se admirou que um homem nessa posição fosse capaz de largar sua vida, cuidando de fazendas, e partir para uma "guerra" pela retomada do direito ao território que o povo da América Latina havia perdido com a chegada dos espanhóis, em 1492.

Na página do Memorial da América Latina, Bolívar é descrito como um homem que

[...] colocou em prática na América ideias de Rousseau, Hobbes e outros filósofos do Iluminismo. Foi fortemente influenciado pelos ideais das Revoluções Americana e Francesa. Descrito por seus biógrafos como homem de pensamento rápido, estratégia mais diplomática e econômica do que bélica [...] (MEMORIAL DA AMÉRICA LATINA, [s.d.]).

Pela descrição realizada, é possível entender que Bolívar detinha um bom conhecimento de importantes pensadores e os utilizava em suas estratégias para realizar a revolução na A. $\mathrm{L}^{2}$., portanto, vê-se que era um homem que, assim como descrito acima, utilizava mais a razão intelectual do que, propriamente, estratégia de guerra em seus combates.
Gilberto Maringoni, no artigo O Bolivar Simbólico, argumenta que a figura do libertador é até hoje utilizada por diversos políticos da A. L., como, por exemplo, por Hugo Chávez, que diz que as ideais que movem seu governo são inspiradas nas de Bolívar.

Mais além, Maringoni argumenta que hoje instaurou-se um culto à imagem e aos ideias do libertador e que

[...] Bolívar não é uma criação ficcional, fruto de um patriotismo exacerbado em alguns países. É mais do que isso. Ele constitui uma necessidade histórica e um recurso destinado a compensar o desalento causado pela frustração de uma emancipação nacional que não se completaria. Bolívar seria o elo histórico com um ideal de soberania, liberdade e justiça. Daí sua força, tanto política quanto como objeto de veneração quase religiosa (MARINGONI, [s. d.], p. 01).

Se essa é uma demonstração do que representa a figura de Bolívar no imaginário da população e na política, tem-se outra representação do mesmo na Literatura, feita por Gabriel García Márquez.

A obra, O general em seu labirinto (1989), não retrata toda a vida de Bolívar e nem seus dias mais áureos. A narrativa começa quando já haviam terminado as batalhas mais importantes de Bolívar. Gabriel García Márquez relata sua última viajem pelo rio Magdalena, já muito doente e prestas a morrer. Essa fase é a menos conhecida da vida de Bolívar, por, justamente, não haver mais fatos importantes para serem documentados pela História, esta que não se preocupa com o indivíduo, em particular, mas que evidencia a vida e os feitos de uma coletividade, o que dificulta uma sondagem mais precisa de autores para a composição dessas personagens históricas, pois os documentos oficiais não se atém a particularidades da interioridade humana. 
Bolívar falece em 1830, aos 47 anos, portanto foi um homem que realizou grandes feitos em pouco tempo de vida, porém, como o romance de García Márquez traz, Bolívar não foi um homem somente ovacionado. Havia quem o odiasse, haviam disputas e rixas políticas, traições, perseguições e, mais do que tudo, muita decepção por parte do general libertador, por não ser entendido por muitas pessoas. No próprio romance há passagens que demonstram que a pior coisa para Bolívar era que as pessoas duvidassem dele ou que contassem mentiras a seu respeito e ele, ao saber de alguma inverdade, lutava até o fim para que as mentiras fossem desmascaradas.

A ideia de García Márquez é interessante, pois o retrata além do general vitorioso e valente que fez história. $\mathrm{O}$ autor do romance traz à tona um sujeito que, apesar de ter contribuído largamente para a independência da A. L., também tinha defeitos e sentimentos, como qualquer ser humano normal, embora tentasse fazer de tudo para mascará-los.

Antonio Candido (2011), ao falar sobre a personagem do romance, diz que "[...] o romance se baseia, antes de mais nada, num certo tipo de relação entre o ser vivo e o ser fictício, manifestada através da personagem, que é a concretização deste" (Candido, 2011, p. 55), ou seja, no caso do romance a ser analisado, percebe-se que o autor tentou realizar essa aproximação do Bolívar humano com o Bolívar histórico, adicionando, claro, aspectos fictícios e próprios do autor, que o delineou de uma maneira particular.

Ainda sobre a personagem, Candido comenta que a mesma necessita aparecer com “[...] o que há de mais vivo no romance; e que a leitura deste dependa basicamente da aceitação da verdade da personagem por parte do leitor (CANDIDO, 2011, p. 54). Isso quer dizer, no caso específico d' O general em seu labirinto, que a representação de Bolívar precisa passar essa sensação ao leitor.
Como se trata de um personagem real e histórico, o autor teve que trabalhar com muitos elementos que já foram construídos sobre essa figura, ou seja, não pôde inventar um personagem de sua própria imaginação, sem ligá-lo a determinados fatos reais e biográficos do Bolívar da realidade. Quando a personagem é um ser real e quando o leitor já conhece algo a respeito dele, o mesmo já vem com uma imagem do sujeito representado e, ao ler a obra, acrescenta as características do autor, mas para que o leitor aceite como verdade o que está lendo, como Candido comenta, não pode haver uma grande distância da retratação da personagem com a realidade documentada sobre a mesma.

Como o romance retrata os últimos tempos de vida do general, mais ou menos o último ano, já no início há uma descrição do general, que acabava de completar 46 anos:

\begin{abstract}
Completara quarenta e seis anos no último mês de julho, mas já sua áspera grenha caribe ficara cinzenta: tinha os ossos desmantelados pela decrepitude prematura, e todo ele se via tão desfeito que não parecia capaz de durar até o próximo julho (GARCÍA MÁRQUEZ, 2000, p. 12).
\end{abstract}

Percebe-se, pela descrição, que o general, como Bolívar era conhecido e chamado, já caminhava para a morte, como ocorreu um ano depois. O que chama a atenção é a maneira com que García Márquez descreve Bolívar. A Professora Dra. Evely Libanori (2002), sobre a retratação da personagem no romance, diz que:

O que se constrói, neste romance, portanto, não é a figura do militar intrépido e glorioso em suas conquistas, embora esta figura não seja negada enquanto passado. Trata-se de contar, não a vida do general mitificado, excessivamente registrada em documentos históricos, mas de contar aquilo que não interessa para os anais históricos: a luta de Bolívar contra a indigência do corpo, em duelo inconsciente com seu destino (LIBANORI, 2002, p. 02). 
A esta altura o general já estava disposto a abandonar o pouco poder que ainda lhe restava e deixar a Colômbia, embarcando para a Europa. Já estava desenganado, não tinha muitos a quem confiar e, mesmo todos sabendo que andava como um moribundo, ainda tinha inimigos dispostos a armar atentados contra sua vida, principalmente o general Santander, apontado, no romance, como uma das principais inimizades do general na época em que história se passa.

Santander não desperdiçava oportunidades de difamar o general, principalmente quando este fracassava em alguma batalha, como, de fato, ocorreu. Sabe-se que Bolívar não era tão bom estrategista de guerra como o era intelectualmente. No romance há a seguinte passagem sobre as "falhas" do general durante as guerras da independência: "desde antes da vitória se dizia que pelo menos três batalhas tinham sido pedidas nas guerras da independência porque ele não estava onde devia, e sim na cama de uma mulher" (García Márquez, 2000, p. 119).

Esse era o maior motivo, segundo os inimigos, para os fracassos em batalhas do general: as mulheres. Segundo sua história, Bolívar foi casado, mas por pouco tempo, pois sua esposa falece e depois tem sua vida rodeada de várias mulheres, muitas passageiras, mas houve quem ficasse famosa por lutar ao seu lado, chamada Manuela Sáenz que, "além de ser a última mulher com que manteve um amor continuado desde a morte de sua esposa, vinte e sete anos antes, era também confidente, a guardiã de seus arquivos e sua leitora mais emotiva” (García Márquez, 2000, p. 31). Manuela também é uma figura histórica e revolucionária conhecida por atuar na luta pela independência das colônias espanholas.

No decorrer do romance, Gabriel García Márquez vai contando a última aventura do general, a maneira como lidava com seus inimigos e, mais do que tudo, retrata a vida de um homem que driblava, diariamente, a inimiga morte.

Todos já suspeitavam do fim do general, inclusive o narrador anuncia que seu fim está próximo. $\mathrm{O}$ único que não se dá conta de sua situação é o próprio Bolívar, que ainda está muito associado aos planos social e físico para pensar na sua própria morte, como um processo ontológico.

Essa ideia de não pensar, não aceitar o próprio fim foi um processo histórico, cultural e social instaurado no Ocidente. Com o advento da Modernidade, maior era o medo e o afastamento desse acontecimento biológico que todo ser vivo está fadado, portanto, aceitável a ideia do general demorar a aceitar sua real situação, afinal de contas, não lhe é natural pensar no próprio fim, ainda mais sendo uma figura tão importante no cenário da A. L. e ainda tão jovem.

Para que se tenha noção do definhamento do general, o autor rememora, em alguns momentos, os tempos áureos do mesmo como "nos primeiros anos de poder [em que] o general não perdia ocasião de oferecer banquetes concorridos e esplêndidos, incitando os convidados a comer e beber até a embriaguez" (García Márquez, 2000, p. 76) para compará-los ao momento preciso que García Márquez queria destacar da vida de Bolívar, ressaltando que " desse passado régio lhe ficaram os talheres pessoais com seu monograma gravado [...]" (García Márquez, 2000, p. 76), ou seja, os tempos de glória já não existiam mais, por uma questão de abalo do poder, inimigos e, mais do que isso, pela saúde, que já não colaborava com os exageros antigos do general.

Em outros momentos, Bolívar parecia contradizer tudo o que seu aspecto físico aparentava, como quando, por exemplo, o general e sua comitiva estavam em Honda e recebeu um convite para um passeio e José Palacios, seu fiel companheiro, se surpreendeu pelo general aceitar e, mais ainda, por descer uma galeria subterrânea. Mais do que isso, 
[...] no caminho de volta, embora tivesse febre alta e a cabeça estalando de enxaqueca, resolveu nadar num remando do rio. [...] nados sem cansaço durante meia hora, mas os que viram suas costelas de cachorro e suas pernas raquíticas não entenderam como podia continuar vivo com tão pouco corpo (GARCÍA MÁRQUEZ, 2000, p. 79).

Em outro momento, na mesma cidade, Bolívar rememorou seus velhos tempos em bailes, nos quais era o último a ir embora, dançando com todas as mulheres que lá estavam e desejassem valsar com ele. No fragmento abaixo nota-se que em algumas circunstâncias o general buscava forças para manter a aparência de ainda ser um homem firme, com saúde.

\begin{abstract}
$\mathrm{Na}$ última noite em Honda já tinha as forças tão reduzidas que precisava se refazer nos intervalos aspirando os vapores do lenço embebido em água-de-colônia, mas valsou com tanto entusiasmo e com maestria tão juvenil que, sem querer, destruiu as versões de que estava à morte (GARCÍA MÁRQUEZ, 2000, p. 81).
\end{abstract}

Jáinstalado em Turbaco, há outras descrições do aspecto físico do general que demonstram o definhar de seu corpo, como se a aparência, cada vez pior, demonstrasse qual a distância que este estava de sua própria morte.

Em um encontro com os três juanes ${ }^{3}$, do partido bolivarista, o general, ao aparecer diante deles, os impressionou, pois seus

[...] ossos eram visíveis através da pele, e não conseguia fixar o olhar. Devia ter consciência do fedor e da quentura de seu hálito, pois tomava o cuidado de falar a distância e quase de perfil. O que mais os impressionou, porém, foi a evidência de que havia diminuído de estatura, a tal ponto que o general Montilla, ao abraçá-lo, teve a impressão de que ele lhe batia pela cintura (GARCÍA MÁRQUEZ, 2000, p. 144).
Se, a essa altura, o general aparentava ser quase um fantasma diante dos demais, isso deveria doer-lhe, pois há indícios na obra de que Bolívar foi um homem muito vaidoso. Vaidade essa que utilizava para aparentar como os pintores, que faziam seus retratos nas épocas gloriosas, o retratavam: “[...] o implantaram na memória oficial com o perfil romano de suas estátuas" (García Márquez, 2000, p. 184), mas com o passar dos anos e o avanço de suas mazelas, não havia mais como mascarar sua aparência carcomida pelas moléstias, pois já não podia apresentar-se como um homem de perfil romano, se nem boa altura lhe restava mais. Aos quarenta e um anos, poucos anos antes de sua morte, o general havia tomado consciência de sua velhice prematura, quando

ainda usava o cabelo comprido até os ombros
amarrado na nuca com uma fita, para maior
comodidade nas batalhas da guerra e do amor,
mas então notou que estava quase branco, e o
rosto murcho e triste. [...]. Nessa noite cortou o
cabelo. Pouco depois, em Potosí, procurando
conter o vendaval da juventude a lhe fugir por
entre os dedos, raspou o bigode e as suíças
(GARCÍA MÁRQUEZ, 2000, p. 190).

Essas mudanças de aparência, que o próprio general provocava em si, além de demonstrarem uma luta pela manutenção do ideal de um general com perfil romano, ao mesmo tempo denotavam que o mesmo estava se entregando, que já não poderia lutar contra o tempo e com as moléstias para ser o mesmo general de outros tempos gloriosos. Bolívar estava se desfazendo de todos os aspectos físicos que o caracterizavam como o El Libertador para se tornar, apenas, Simón Bolívar, um homem, como outro qualquer, que está a caminho de sua morte e que, mais do que tudo, começa a perceber, mesmo sem confessar, que seu fim está próximo.

Porém, mesmo moribundo, Bolívar 
conseguiu chegar ao seu aniversário de quarenta e sete anos e ainda comemorou por estar vivo, mas, talvez sabendo que não chegaria a completar quarenta e oito. Há dezessete dias de sua morte, o general foi examinado pelo médico Alexandre Prosper Révérend, que “[...] não precisou lhe tomar o pulso para saber que começara a morrer havia anos" e "[...] atribuiu tanta importância às calamidades do corpo como ao padecimento moral" (García Márquez, 2000, p. 247), ou seja, não foram só as doenças que o foram matando, mas sua consciência, seus inimigos, todo o maranhado de coisas que envolvem ser um homem com a postura e o poder que teve o general Bolívar.

Em seus últimos dias, "[...] mandava borrifar o quarto com água de colônia, e continuou tomando seus banhos ilusórios, barbeandose com as próprias mãos, escovando os dentes com um encarniçamento feroz, num esforço sobrenatural para se defender das imundícies da morte" (García Márquez, 2000, p. 259). Enquanto o general tentava ludibriar a morte com seus truques e perfumes, seus companheiros e demais soldados já se preparavam para seu futuro funeral, discutindo quanto e da onde tirariam o valor que seria necessário para seu enterro, já que o general, no final de sua vida, já não era mais um homem de grandes posses, portanto, dependeria da bondade alheia para ter um caixão em que pudesse "descansar em paz".

O Bispo fora chamado para a extrema unção. Fernanda Barriga, sua cozinheira, juntamente com outras índias, fazia orações fúnebres em sua língua. Uma banda de Mamatoco fora chamada para tocar a música preferida do general, La trinitaria, ao pé de sua janela. Os escravos pararam seus afazeres para contemplá-lo, todos prevendo que era chegado o fim, mesmo que Bolívar teimasse, até o último instante, em não aceitar, porém, na hora de sua morte "[...] estremeceu à revelação deslumbrante de que a corrida louca entre seus males e seus sonhos chegava naquele instante à meta final. $\mathrm{O}$ resto eram as trevas. - Carajos! - suspirou. - Como vou sair deste labirinto?” (García Márquez, 2000, p. 266).

Esse labirinto, a morte, já era demasiado longo e confuso para que o general tivesse tempo de sair. Era uma batalha perdida. Libanori, sobre a representação do labirinto, comenta que

\begin{abstract}
Se o labirinto pressupõe um complexo cruzamento de diversos caminhos, alguns dos quais não oferecem saída, pode-se dizer que a vida em curso pressupõe uma sinuosa estrutura labiríntica. Há diversas possibilidades de caminho que se cruzam, se comunicam, se fecham. A morte, no entanto, interrompe todos eles (LIBANORI, 2002, p. 01).
\end{abstract}

Ainda sobre o momento da morte de Bolívar, no último parágrafo do romance, García Márquez descreve lindamente a maneira como o general Bolívar viu seu mundo em seus últimos segundos de vida:

Examinou o aposento com a clarividência de quem chega ao fim, e pela primeira vez viu a verdade: a última cama emprestada, o toucador lastimável cujo turvo espelho de paciência não o tornaria a refletir, o jarro d'água de porcelana descascada, a toalha e o sabonete para outras mãos, a pressa sem coração do relógio octogonal desenfreado para o encontro inelutável de 17 de dezembro, à uma hora e sete minutos de sua tarde final. Então cruzou os braços contra o peito e começou a ouvir as vozes radiosas dos escravos contando a salve-rainha das seis nos trapiches, e avistou no céu pela janela o diamante de Vênus que ia embora para sempre, as neves eternas, a trepadeira nova cujas campânulas amarelas não veria florescer no sábado seguinte na casa fechada pelo luto, os últimos fulgores da vida que nunca mais, pelos séculos dos séculos, tornaria a se repetir (GARCÍA MÁRQUEZ, 2000, p. 266).

O trecho acima, o momento da morte do general e sua sensação, descrita por García Márquez, revelam ao personagem que a morte é o 
instante em que o ser humano percebe, aos que têm esse momento, a linha tênue que liga o ser ao deixar de ser, revelado por Bolívar como o único e maior momento de verdade na vida de um ser humano, o momento no qual ele pôde tomar consciência de que seriam seus últimos segundos como um ser vivo, que jamais tornaria sequer a ver sua imagem refletida em um espelho e o tempo, representado pelo relógio, atuava, desenfreadamente, como um inimigo nesta pequena viajem de lucidez, pois caminhava rapidamente para o fim, para o deixar de ser, sentir, ver e ouvir do general.

Neste último parágrafo, García Márquez conseguiu fazer com que a personagem lembrasse um ser vivo, ou seja, um sujeito capaz de "[...] manter certas relações com a realidade do mundo, participando de um universo de ação e de sensibilidade que se possa equiparar ao que conhecemos na vida" (Candido, 2011, p. 65).

O general faleceu em 1830, na quinta de San Pedro Alejandrino, e foi velado na casa da alfândega velha, lugar em que permaneceu instalado em seus últimos dias, “[...] exposto em câmara-ardente o seu corpo embalsamado, com a sobrecasaca azul de sua patente, sem os oito botões de ouro que alguém iria arrancar na confusão da morte" (García Márquez, 2000, p. 247).

Diante do exposto sobre o romance, passarse-á, agora, para a análise da obra cinematográfica sobre Simón Bolívar, Libertador (2013), dirigida por Alberto Arvelo, a fim de se verificar como a figura de Bolívar é representada em cada esfera artística.

Sobre o romance e a obra cinematográfica, tem-se que levar em consideração que são olhares distintos para o mesmo personagem, e que se tratam de duas linguagens diferentes, a literatura e o cinema, que, por conseguinte, são produzidas e recepcionadas pelo público de formas distintas, mas isso não impede que se possa ter uma noção de como ocorre a releitura de uma figura história nessas duas esferas, como será a partir de agora.

Como não há o roteiro do filme disponível, fica mais difícil poder repassar ao leitor como o personagem Bolívar é caracterizado na obra, como foi possível fazer com a obra literária de García Márquez, que descreveu a figura do general em seu último ano de vida.

A obra cinematográfica inicia em 1828, em Bogotá, mas retorna no tempo, pelo recurso do flashback, retratando aspectos de sua infância, casamento, memórias e como se tornou a figura lendária, conhecida como El libertador.

Entre a obra literária e o filme, portanto, há uma diferença de um ano em relação ao tempo da narrativa, mas no cinema é possível, através do recurso citado acima, voltar com maior facilidade no tempo e circular por um universo temporal maior. Na literatura isso também é possível, mas é algo que requer um domínio distinto para aplicação na obra. Quem rememora acontecimentos passados no romance é o narrador, como na seguinte passagem: "apenas três anos antes, quando regressou das estéreis guerras do sul sob o peso da maior quantidade de glória que qualquer americano vivo ou morto jamais havia merecido [...]" (García Márquez, 2000, p. 46). Aqui o recurso de voltar no tempo serve para que o leitor veja o que já foi do general Bolívar e como o mesmo era no tempo da narrativa, ou seja, o narrador quis mostrar que os tempos de batalhas gloriosas já haviam passado.

A descrição da personagem Bolívar também é feita de uma maneira diferente da do romance. A obra cinematográfica não retrata a personagem em seus momentos de fraqueza ou derrota, mas trouxe ao público aquela imagem do general de perfil romano, como García Márquez fala em seu romance, que era a maneira como os pintores o retratavam em seus tempos áureos.

Quem interpreta Bolívar é o ator Édgar Ramírez, homem que poderia representar a 
jovialidade e a beleza características do general. Em tese, o herói é, na maioria das vezes, um homem bonito e sedutor, atributos que, aliados à força, fortalecem a fórmula do herói cinematográfico e, claro, a escolha do ator para desempenhar esta função é fundamental.

Paulo E. Salles Gomes (2011, p. 114) diz que "a personagem de ficção cinematográfica, por mais fortes que sejam suas raízes na realidade ou em ficções pré-existentes, só começa a viver quando encarnada numa pessoa, num ator". Isso significa a aproximação da revelação da profunda ambiguidade da personagem cinematográfica (Gomes in Candido, 2011,p. 114), o que demonstra que, diferentemente de uma personagem literária, a cinematográfica, representada pelo ator já fica delimitada ao mesmo, ou seja, pensa-se em Bolívar a partir da imagem do ator, o que gera ambiguidades, pois a figura história pode não ser nada daquilo que o ator e sua abordagem da personagem representam.

No caso das duas obras, sabendo quem é o Bolívar do cinema, percebe-se a discrepância entre este e o Bolívar descrito por García Márquez, o que gera também, no caso da comparação entre as duas representações, a ambiguidade que Gomes comenta. Ademais das características físicas, o personagem Bolívar, no filme, como já fora citado, aparenta ser além do Bolívar "mito", que até hoje é disseminado, ou seja, não há uma caracterização muito humana na obra. O personagem é, a todo momento, o galã herói que salvou a América e que sofreu, sim, mas soube driblar os atritos com certa facilidade e malandragem. Não há degeneração e a degradação do corpo e da consciência do general, como na obra literária. Apesar do filme não se fixar em um período preciso da vida do general, acaba quando o general é emboscado por soldados, antes que ele fosse para a Venezuela. Esse período coincide com o tempo analisado na obra literária, pois foi dezesseis dias antes do general morrer.

$\mathrm{Na}$ obra literária, a poucos dias de seu falecimento, Bolívar já estava entregue, de cama e muito mal. No filme, não há a retratação dos dias finais, como ocorre no livro, pelo contrário, Bolívar ainda permanece com as mesmas características: cabelos longos, jovem, forte e bonito. Não se percebe indícios de fraqueza física ou espiritual na obra cinematográfica, diferente da obra literária.

Sobre a retratação de Bolívar na obra literária pode-se estabelecer uma relação com o que Candido coloca sobre a existência da personagem: "no romance, podemos variar relativamente a nossa interpretação da personagem; mas o escritor lhe deu, desde logo, uma linha de coerência fixada para sempre, delimitando a curva da sua existência e a natureza do seu modo-de-ser" (Candido, 2011, p. 58-59). O que Candido aborda serve para que se entenda que a personagem, no romance, é retratada a partir de um período determinado, o que delimita a curva de sua existência e seu modo de ser e agir. O general, em seus últimos anos de vida, já não é o mesmo de outros anos, até porque, historicamente, o espaço em que vivia e por qual lutava já não era o mesmo e os objetivos, também, já eram diferentes. $\mathrm{Na}$ obra cinematográfica, a delimitação da existência da personagem já é diferente, mesmo porque o cinema dispõe de recursos que possibilitam o espectador visualizar, com mais facilidade, mudanças de tempo, espaço e perspectiva.

Mais um indício de que no cinema não seria interessante revelar os últimos dias do general é que o filme não termina com sua morte, mas com essa emboscada sofrida em um cais. O fim do general não foi heroico, como nos filmes de guerras. Bolívar não morreu em campo de batalha, lutando pela América, portanto, não poderiam fazer um final emocionante e épico, glorificando ainda mais a figura da personagem. Como Bolívar 
morreu oficialmente de tuberculose, não teria com, criar esse final heroico, ou seja, se o retratassem em sua morte, o expectador veria um Bolívar humano, que não morreu com uma espada na mão, mas que se entregou como qualquer outro pobre mortal, vítima das mazelas do corpo e da mente, que o cercaram desde muito cedo.

$\mathrm{Na}$ obra literária, García Márquez soube descrever esse momento da morte de uma maneira muito natural e real, como, provavelmente, muitos já o tiveram e, mesmo assim, conseguiu fazer do trecho final, já citado acima, um dos mais poéticos e emocionantes da obra. Dessa forma, possível ver o herói Bolívar morrer moribundo, mas, ainda sim, como El Libertador.

Como já foi dito, trata-se de uma linguagem diferente da literária e precisa ter seus aspectos apelativos a fim de apreender o leitor/ expectador de outras formas: através da imagem, primeiramente, e outros recursos, como a ironia, o drama, a comoção. A obra literária pode ter todos esses aspectos, mas são introduzidos na obra de forma distinta e sentidos pelo leitor de outra maneira. O cinema é algo que precisa ser imediato. A literatura tem um tempo de apreciação maior e diferente do que acontece no cinema.

\section{Considerações finais}

Levando em consideração as duas obras analisadas: o romance $O$ general em seu labirinto e a obra cinematográfica Libertador, pode-se dizer que ambas trazem o perfil do general Simón Bolívar em destaque. O romance aborda o último ano de vida de Bolívar, portanto, já não é uma fase áurea do general. Entende-se que a perspectiva de García Márquez foi mostrar um lado mais humano dessa figura mítica e histórica, revelando sua luta contra a morte.

O filme começa a dois anos de sua morte, mas faz vários flashbacks para que o espectador tenha uma noção da vida do general, como um todo. A obra cinematográfica retrata a figura de Bolívar e seus feitos de uma maneira mais heroica do que García Márquez o faz e não retrata sua morte. Talvez a ideia fosse a de preservar o mito na memória do espectador, já que grandes figuras da História podem até morrer, biologicamente, mas permanecem vivas no imaginário da população, tendo seus feitos passados por gerações e gerações.

São duas obras e duas maneiras de retratar e passar a imagem do general Simón Bolívar. Além de todas as intenções, não esquecendo o caráter ficcional das obras, não se pode deixar de notar a representatividade das mesmas para a permanência da imagem dessa figura tão importante para a História da América Latina.

Além da representatividade da figura lendária de Bolívar, ambas as obras são importantes para que se conheça um dos períodos mais importantes da História da América Latina, o da independência das colônias que estavam sob domínio espanhol. A figura de Simón Bolívar, como herói, só existe a partir desse fato histórico.

\section{Referências}

ARVELO, Alberto; HAMMACHER, Winfried; LOEHNERT, Ana. Libertador. [Filmevídeo]. Produção de Ana Loehnert e Winfried Hammacher, direção de Alberto Arvelo. Venezuela/Espanha, 2013. 119 min.

CANDIDO, Antonio. et al. A personagem de ficção. São Paulo: Perspectiva, 2011.

FUNDAÇÃO MEMORIAL DA AMÉRICA LATINA. Simón Bolívar. Disponível em: <http://www.memorial.org.br/simon-bolivar/>. Acesso em 05 Jun 2015.

LIBANORI, Evely Vânia. A presença da morte 
no romance $\mathbf{O}$ general em seu labirinto, de Gabriel García Márquez. In: CONGRESSO BRASILEIRO DE HISPANISTAS, 2, 2002, São Paulo. Associação Brasileira de Hispanistas. Disponível em: $<$ http://www.proceedings.scielo. br/scielo.php?script $=$ sci_arttext\&pid $=$ MSC00 00000012002000300020\&lng $=$ en\&nrm $=$ abn > . Acesso em: 21 Jun. 2015.

MARINGONI, Gilberto. O Bolívar simbólico.

Disponível em: http://www2.uol.com.br/ historiaviva/artigos/o_bolivar_simbolico.html. Acesso em 05 Jun. 2015.

GARCÍA MÁRQUEZ, Gabriel. O general em seu labirinto. Trad. Moacyr Wernek de Castro. Rio de Janeiro: Record, 2000.

Data de envio: 15/12/2016

Data de aceite: 15/06/2017 